\title{
STUDI ETNOBOTANI PEMANFAATAN JENIS-JENIS MANGROVE SEBAGAI TUMBUHAN OBAT DI SULAWESI
}

\author{
Rini Purwanti \\ Balai Penelitian dan Pengembangan Lingkungan Hidup dan Kehutanan Makassar \\ J1. Perintis Kemerdekaan Km. 16,5 Makassar \\ E-mail: rnpurwanti_up@yahoo.co.id
}

\begin{abstract}
Abstrak
Salah satu hasil hutan non kayu mangrove yang penting adalah sebagai bahan baku obatobatan. Eksplorasi dan penelitian mengenai potensi mangrove sebagai bahan baku obat telah banyak dilakukan, tetapi penyebarluasan potensi dan khasiat mangrove ini belum banyak dilakukan dengan optimal sehingga masih banyak pihak yang kurang bahkan belum mengetahuinya. Tujuan penelitian ini adalah untuk mengkaji bentuk-bentuk pemanfaatan tumbuhan mangrove oleh masyarakat pesisir di Sulawesi. Metode pengumpulan data melalui survey lapangan dan wawancara terhadap masyarakat yang berada di sekitar kawasan hutan mangrove. Hasil penelitian menunjukkan bahwa masyarakat di pesisir Sulawesi baru mengenal 5 (lima) jenis tumbuhan mangrove sebagai bahan obat-obatan yaitu jenis Rhizophora sp sebagai obat luka akibat digigit ikan dan kepiting, muntaber (akar muda), dan sebagai pewarna pakaian/jala ikan (kulit), Xylocarpus granatum (buah) sebagai obat gatal-gatal kulit serta dapat menghaluskan kulit, Avicennia sp sebagai obat gatal-gatal pada kulit, Ceriops tagal dapat menguatkan gigi biasa digunakan sebagai pengganti sirih (buah) dan obat encok dan kurap (daun). Minimnya pengetahuan masyarakat ini diakibatkan karena sosialisasi yag belum sampai ke mereka, dan pengetahuan ini hanya mereka dapatkan secara turun temurun dari orang tua mereka. Oleh sebab itu, kegiatan sosialisasi tentang manfaat mangrove sebagai tumbuhan obat perlu lebih ditingkatkan lagi.
\end{abstract}

Kata kunci: Etnobotani, mangrove, tumbuhan obat, Sulawesi

\begin{abstract}
Mangrove is one of the non timber forest product and is able to be utilize as raw material of medicines. Some researches and explorations of mangrove as raw material for medicines have been undertaken, however the lack of information of this purposes as a result of the lack of dissemination of this type of utility of mangrove has not been spread out widely and optimum. The aim of this research is to do some social study of the form of the utility of mangrove by coastal community. The research used interview and survey data collection as the research method. The result showed that the community hadcertain knowledge for five mangrove species for medicinal purposes, i.e.: Rhizophora sp, to curing wound of fish and crab bites, vomiting and diarrhea (young root) and for dying clothing and fishnets (skin); (fruit of) Xylocarpus granatum as medicine for curing skin itching and skin smoother; Avicennia sp as medicine for curing skin itching as well; Ceriops tagal for strengthen teeth and used as a substitute of betel leaf (fruit) and gout and ringworm (leaf). The lack of community knowledge was due to the lack of socialization towards them. They received that knowledge traditionally from generation to generation. Therefore the
\end{abstract}


socialization activities of the utility of mangrove as medicinal plant was needed to be improved and increased.

Keywords: Ethnobotany, mangrove, medicinal plants, Sulawesi

\section{PENDAHULUAN}

Hutan mangrove merupakan suatu tipe hutan yang tumbuh di daerah pasang surut, terutama di pantai yang terlindung, laguna dan muara sungai yang tergenang pada saat pasang dan bebas dari genangan pada saat surut yang komunitas tumbuhannya bertoleransi terhadap garam (Kusmana et al, 2003). Menurut FAO (2007), hutan mangrove merupakan tipe hutan yang khas dan tumbuh di sepanjang pantai atau muara sungai yang dipengaruhi oleh pasang surut air laut. Mangrove banyak dijumpai di wilayah pesisir yang terlindung dari gempuran ombak dan daerah yang landai di daerah tropis dan sub tropis.

Mangrove mempunyai berbagai fungsi, yaitu fungsi fisik untuk menjaga kondisi pantai agar tetap stabil, melindungi tebing pantai dan tebing sungai, mencegah terjadinya abrasi dan intrusi air laut, serta sebagai perangkap zat pencemar. Fungsi ekologis mangrove adalah sebagai penyedia nutrien bagi biota perairan, tempat pemijahan dan asuhan (nursery ground) berbagai macam biota, penahan abrasi pantai, penahan amukan angin taufan dan tsunami, penyerap limbah, pencegah intrusi air laut, dll. Dilihat dari segi sosial dan ekonomi, hutan mangrove juga berfungsi sebagai tempat wisata alam, lokasi pendidikan dan penelitian, serta penyedia berbagai hasil hutan kayu dan non kayu. Salah satu hasil hutan non kayu mangrove yang penting adalah sebagai bahan baku obat-obatan.

Purnobasuki (2004) menyatakan bahwa mangrove kaya akan senyawa steroid, saponin, flavonoid dan tannin. Senyawa saponin dari tumbuhan adalah glikosida dari triterpene dan steroid, yang larut dalam air dan mempunyai kemampuan membentuk buih sabun bila dikocok di air. Penggunaan saponin sebagai deterjen alam dan racun ikan telah dikenal oleh masyarakat tradisional. Sifat farmatikal yang berhubungan dengan obat Cina 'ginseng' merupakan atribut dari senyawa saponin. Saponin tumbuhan seperti halnya dioscin, bernilai komersial setelah ditemukan sebagai bahan untuk hormone steroid sintetis (Correl, et al. 1955) dalam Purnobasuki (2004). Manfaat lain dari saponin adalah sebagai spermisida (obat kontrasepsi laki-laki); antimikrobia, anti peradangan, dan aktivitas sitotoksik (Mahato et al., 1988) dalam Purnobasuki (2004). Salah satu tumbuhan mangrove penghasil saponin steroid dan sapogenin adalah Avicennia officinalis yang banyak tumbuh di pesisir Indonesia.

Bandaranayake (1998) dalam Purnobasuki (2004) telah menemukan ada 16 jenis mangrove baik mangrove sejati, minor maupun asosiasinya yang berkhasiat obat, sedangkan Kusmana et al, 2008 menyatakan terdapat 20 (dua puluh) jenis mangrove dan asosiasinya yang memiliki kandungan obat diantaranya untuk obat demam, penyakit kulit, asma, rematik, luka karena gigitan binatang dan lain sebagainya.

Umumnya pengetahuan pengobatan tradisional hanya dikuasai oleh kaum tua. Generasi muda saat ini kurang termotivasi untuk menggali pengetahuan dari kaum tua, dan lambat laun mulai ditinggalkan karena berbagai faktor penyebab. Kondisi seperti ini, menjadikan warisan tradisional lambat laun akan mengalami kepunahan di tempat aslinya (Noorcahyati, 2012). Karena itu, perlu ada upaya untuk mendokumentasikan pengetahuan pengobatan tradisional yang seiring dengan upaya pelestarian tumbuhan berkhasiat obat untuk pengetahuan, konservasi dan kesejahteraan masyarakat. Salah satu cara pendokumentasian tersebut adalah melalui kajian etnobotani tumbuhan berkhasiat obat.

Etnobotani secara terminologi dapat dipahami sebagai hubungan antara botani (tumbuhan) yang terkait dengan etnik (kelompok masyarakat) di berbagai belahan bumi, 
dan masyarakat umumnya. Studi etnobotani bermanfaat ganda, karena selain bermanfaat bagi manusia dan lingkungan, dan perlindungan pengetahuan tersebut, melalui perlindungan jenis jenis tumbuhan yang digunakan (Suryadarma 2008). Menurut Purwanto (2000), etnobotani merupakan ilmu yang mempelajari hubungan timbal balik secara menyeluruh antara masyarakat lokal dengan alam lingkungannya yang meliputi pengetahuan tentang sumberdaya alam tumbuhan. Karena itu, etnobotani berpotensi mengungkapkan system pengetahuan tradisional dari suatu kelompok masyarakat atau etnik mengenai keanekaragaman sumberdaya hayati, konservasi dan budaya.

Eksplorasi dan penelitian mengenai potensi mangrove sebagai bahan baku obat telah banyak dilakukan, tetapi penyebarluasan potensi dan khasiat mangrove ini belum banyak dilakukan dengan optimal sehingga masih banyak pihak yang kurang bahkan belum mengetahuinya. Oleh sebab itu, dalam tulisan kali ini peneliti ingin mengetahui apakah pemanfaatan mangrove sebagai bahan obat-obatan juga telah diketahui oleh masyarakat di Sulawesi, terutama oleh masyarakat yang hidup di sekitar hutan mangrove? Jika "Ya", jenis-jenis apa saja yang telah mereka pergunakan? Apa manfaatnya dan bagaimana cara mengolahnya? Penelitian ini bertujuan untuk mengkaji bentuk-bentuk pemanfaatan tumbuhan mangrove oleh masyarakat pesisir di Sulawesi.

\section{METODE PENELITIAN}

\section{A. Waktu dan Lokasi Penelitian}

Penelitian ini merupakan bagian dari kegiatan penelitian yang dilaksanakan di Taman Nasional Rawa Aopa Watumohai (TNRAW), Kendari (Sulawesi Tenggara), Kabupaten Luwu Timur (Sulawesi Selatan) pada tahun 2011, dan di Taman Nasional Kepulauan Togean (TNKT) (Sulawesi Tengah) pada tahun 2012.

Secara geografis, TNRAW terletak antara 121 ${ }^{0} 44^{\prime}-122^{0} 44$ BT dan $4^{0} 22^{\prime}-4^{0} 39$ LS. Sedangkan secara administratif pemerintahan, TNRAW terletak di Provinsi Sulawesi Tenggara yang berbatasan dengan lahan budidaya masyarakat di 68 desa dan 9 kecamatan. Sabuk hijau berupa hutan bakau menjadi salah satu ciri TNRAW. Ekosistem mangrove ini membentang 24 kilo meter sepanjang Pantai Lanowulu mulai dari Muara Sungai Roraya sampai Sungai Langkowala dengan luas sekitar 6. 173 hektar.

Luwu Timur merupakan salah satu Kabupaten di Propinsi Sulawesi Selatan yang beribukota di Malili, secara geogarafis terletak antara $2^{0} 0300-3^{0} 0025$ LS dan antara $119^{0} 2856-121^{0} 4727$ BT. Daerah ini berbatasan dengan Propinsi sulawesi Selatan di utara, Propinsi Sulawesi Tengah di timur, Propinsi sulawesi tenggara dan Teluk Bone di selatan, Kabupaten Luwu di barat. Luas wilayah derah ini adalah 6.944,88 Km2. Hasil analisa citra satelit menunjukkkan bahwa luas hutan mangrove sepanjang pesisir Kabupaten Luwu Timur adalah 8.672,4 Ha.

Kepulauan Togean terletak di tengah Teluk Tomini yang memanjang dari barat ke timur pada koordinat $0^{0} .08^{\prime} 21^{\prime}{ }^{\prime}-0^{0} .45^{\prime} 12^{\prime}$ ' LS and $121^{\circ} .33^{\prime} 21^{\prime}{ }^{\prime}-122^{0} .23$ '36 BT, dengan luas daratan kurang lebih 755,4 $\mathrm{km}^{2}$. Kepulauan Togean terdiri dari kurang lebih 25 pulau besar dan kecil. Secara administratif, kepulauan Togean termasuk ke dalam wilayah kabupaten Tojo Una-Una, Sulawesi Tengah. Menurut data BKSDA dan BAPPEDA Poso, luas hutan mangrove kepulauan Togean diperkirakan sekitar 4.800 ha yang tersebar di beberapa pulau besar seperti Talatakoh, Togean, Batudaka, dan sebagian pulau Walea Bahi. Keberadaan hutan mangrove (hutan bakau) di kepulauan Togean selain menjaga keutuhan garis pantai juga menyokong potensi perikanan dan ekosistem terumbu karang yang menjadi andalan kehidupan masyarakat Togean. Meski memiliki luasan yang tak terlalu besar, namun hutan mangrove memiliki fungsi yang sangat penting bagi kepulauan 
Togean yang merupakan kawasan pulau-pulau kecil. Peta lokasi kegiatan penelitian dapat dilihat pada Gambar 1.

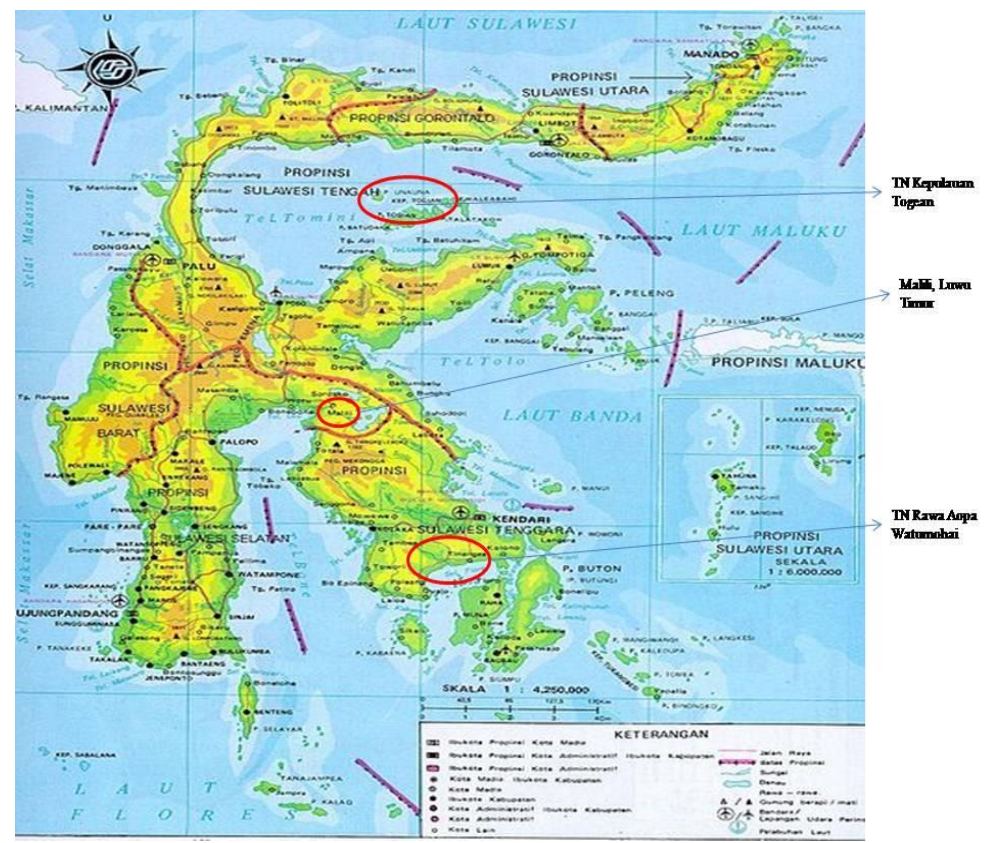

Gambar 1. Peta Lokasi Penelitian

\section{B. Bahan dan Peralatan}

Alat yang digunakan dalam penelitian ini yaitu alat tulis, kamera, kalkulator, recorder, parang, gunting stek, kuisioner dan seperangkat komputer dengan perangkat lunak Microsoft Office 2007 (Word, Excel) untuk pengolahan data.

Bahan yang digunakan dalam penelitian ini adalah kuisioner, kertas koran, label gantung, tali rafia, sampel tumbuhan dan plastik.

\section{Prosedur Penelitian dan Analisa Data}

Penelitian ini dilakukan untuk memperoleh data dan informasi tentang pemanfaatan tumbuhan mangrove sebagai bahan obat-obatan leh masyarakat pesisir. Penelitian ini dilakukan dalam beberapa tahap, yaitu studi pustaka, observasi lapangan dan wawancara, serta pengolahan dan analisis data. Data yang diambil terdiri atas data primer dan data sekunder. Data primer merupakan data yang diambil secara langsung di lapangan berupa hasil wawancara dengan responden, serta hasil diskusi dengan tokoh masyarakat serta dukun atau tabib yang biasa mengobati masyarakat sekitar. Wawancara secara informal dilakukan dengan bantuan daftar pertanyaan yang telah dibuat. Penetapan responden dilakukan menggunakan pendekatan metode purposive random sampling yaitu sampel diambil secara sengaja berdasarkan tujuan penelitian. Dalam metode ini, wawancara dilakukan terhadap sasaran responden yang ditentukan secara terpilih (Hamidu, 2009). Data sekunder adalah data yang diambil dari hasil penelitian atau laporan maupun publikasi yang dilakukan pihak lain.

Data yang telah dikumpulkan selanjutnya dianalisis deskriptif kualitatif untuk mendapatkan informasi tentang bentuk-bentuk pemanfaatan tumbuhan mangrove oleh masyarakat sebagai bahan obat, bagian yang digunakan serta cara pengolahannya. 


\section{HASIL DAN PEMBAHASAN}

\section{A. Pengetahuan Responden tentang Mangrove sebagai Tumbuhan Obat}

Menurut Notoatmodjo (2007), pengetahuan merupakan hasil dari tahu dan ini setelah orang melakukan penginderaan terhadap obyek tertentu. Penginderaan terjadi melalui panca indera manusia, yakni indera penglihatan, pendengaran, penciuman, rasa dan raba. Sebagaian besar pengetahuan manusia diperoleh melalui mata dan telinganya. Pengetahuan responden tentang manfaat mangrove sebagai tumbuhan obat dapat dilihat dari sejauh mana pengetahuan mereka dalam memanfaatkan mangrove sebagai tumbuhan obat serta bagaimana aplikasinya dalam kehidupan sehari-hari. Pengetahuan responden tentang pemanfaatan hutan mangrove sebagai tumbuhan obat di tiga (3) lokasi penelitian yaitu di Sulawesi Selatan, Sulawesi Tengah dan Sulawesi Tenggara dapat dilihat pada Gambar 2.

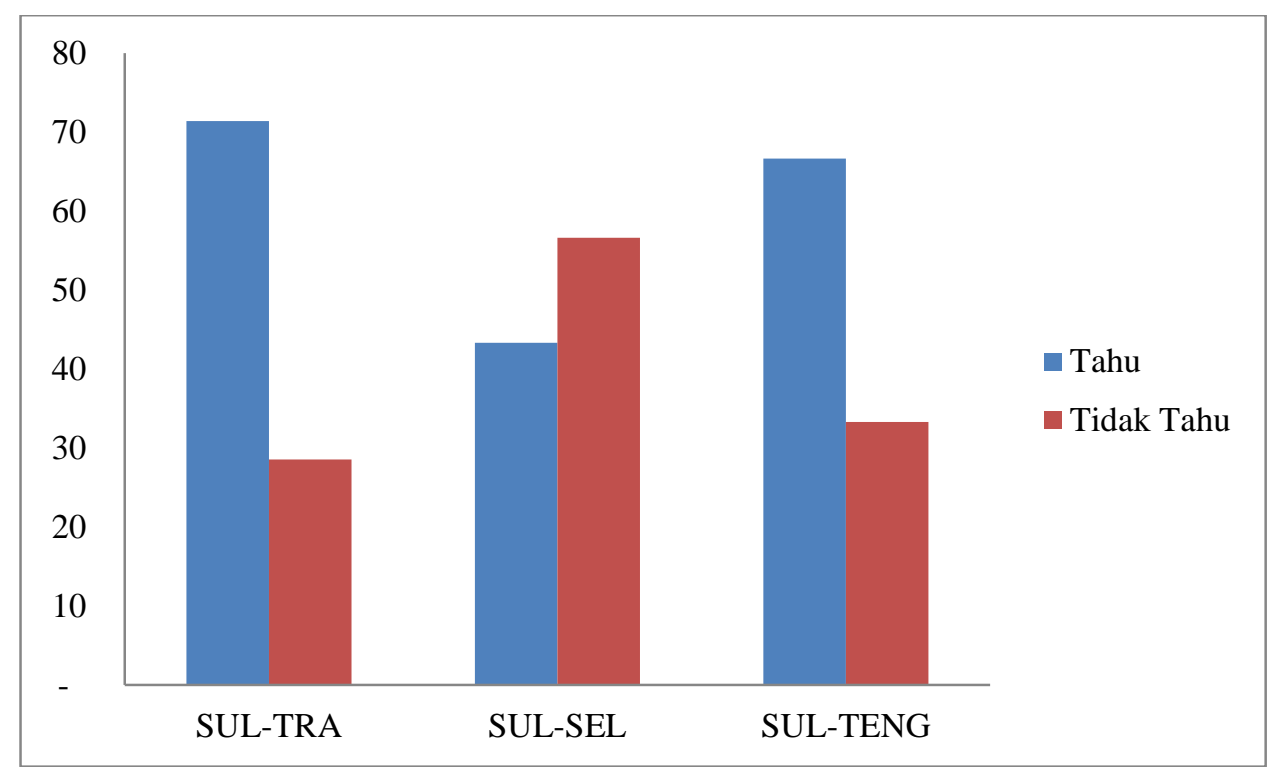

Gambar 2. Diagram Persentase Tingkat Pengetahuan Responden tentang Manfaat Mangrove sebagai Tumbuhan Obat

Berdasarkan diagram Gambar 2, dapat dilihat bahwa sebanyak 71\% (25 orang) responden di Sulawesi Tenggara (Sul-Tra) mengatakan bahwa mereka mengetahui manfaat mangrove sebagai tumbuhan obat, sedangkan 29\% (10 orang) lainnya menyatakan bahwa mereka tidak mengetahuinya. Sebanyak 43\% (13 orang) responden di Sulawesi Selatan (Sul-Sel) mengatakan bahwa mereka mengetahui dan 57\% (17 orang) mengatakan tidak tahu. Sementara di Sulawesi Tengah (Sul-Teng) sebanyak 67\% (20 orang) responden menyatakan tahu dan 33\% (10 orang) responden tidak tahu manfaat mangrove untuk obat. Bagi responden di Sul-Tra dan Sul-Teng lebih banyak yang tahu daripada yang tidak tahu karena pada dasarnya mereka banyak melakukan aktifitas di sekitar hutan mangrove dan tingkat ketergantungan mereka juga sangat tinggi terhadap hutan mangrove. Jika masyarakat sakit, akses menuju rumah sakit atau puskesmas cukup susah karena hanya bisa dijangkau dengan naik perahu saja, sehingga mau tidak mau mereka harus belajar dari alam terutama untuk pengobatan penyakit-penyakit tertentu seperti sakit perut, demam, luka ringan dan sebagainya. Pengetahuan yang mereka peroleh tersebut biasanya merupakan informasi turun temurun dari orang tua mereka dan ini yang kemudian mereka masih coba pertahankan sampai saat ini. 
Hal ini berbeda dengan masyarakat di Sulawesi Selatan khususnya di Kabupaten Luwu Timur yang berada di daratan sehingga jika mereka sakit, akses untuk ke rumah sakit atau puskesmas cukup mudah sehingga tidak lagi menggantungkan pada bahan-bahan alam untuk pengobatan sakitnya tersebut. Jadi pada dasarnya mereka tahu bahwa mangrove mempunyai khasiat untuk pengobatan beberapa penyakit tertentu, tetapi untuk aplikasinya sudah sangat jarang ditemui lagi. Masyarakat lebih memilih menggunakan obat-obat kimia yang sudah banyak dijual bebas di pasaran daripada harus meracik atau merebus-rebus daun lagi.

\section{B. Pemanfaatan Mangrove sebagai Tumbuhan Obat}

Berdasarkan hasil wawancara dengan responden terdapat beberapa macam tanaman mangrove yang bisa dijadikan sebagai bahan obat-obatan yaitu daun dan kulit Avicennia marina, buah Xylocarphus granatum, kulit Rizophora mucronata/apiculata (bakau), Bruguiera gymnorrhiza (sala-sala), dan Gandi-gandi (Ceriops tagal). Untuk lebih jelasnya dapat dilihat pada Tabel 1.

Tabel 1. Jenis Mangrove dan Bagian yang dimanfaatkan oleh Responden

\begin{tabular}{|c|c|c|c|c|}
\hline 1. & \multirow[t]{4}{*}{ Sul-Sel } & $\begin{array}{l}\text { Buli } \\
\text { granatum })\end{array}$ & Buah & Obat gatal/bekas cacar \\
\hline 2. & & $\begin{array}{l}\text { Bakau (Rizophora } \\
\text { apiculata /mucronata) }\end{array}$ & Kulit & Pewarna pakaian \\
\hline 3. & & $\begin{array}{l}\text { Lesse-lesse } \quad \text { (Avicennia } \\
\text { marina) }\end{array}$ & Daun & Obat gatal \\
\hline 4. & & $\begin{array}{l}\text { Gandi-gandi } \quad \text { (Ceriops } \\
\text { tagal) }\end{array}$ & Buah & $\begin{array}{l}\text { Pengganti } \\
\text { (menguatkan gigi) }\end{array}$ \\
\hline 1. & \multirow[t]{4}{*}{ Sul-Tra } & \multirow{2}{*}{$\begin{array}{l}\text { Bakau (Rizophora } \\
\text { apiculata /mucronata) }\end{array}$} & daun & $\begin{array}{l}\text { Luka digigit kepiting dan } \\
\text { menetralisir racun duri ikan }\end{array}$ \\
\hline 2. & & & $\begin{array}{l}\text { Akar } \\
\text { muda }\end{array}$ & $\begin{array}{l}\text { Luka digigit kepiting dan } \\
\text { menetralisir racun duri ikan }\end{array}$ \\
\hline 3. & & $\begin{array}{l}\text { Buli } \\
\text { granatum })\end{array} \quad$ (Xylocarphus & Buah & $\begin{array}{l}\text { Obat gatal dan penghalus } \\
\text { kulit }\end{array}$ \\
\hline 4. & & Tangir (Ceriops tagal) & Daun & Obat encok, kurap \\
\hline \multirow{2}{*}{1.} & \multirow{3}{*}{$\begin{array}{l}\text { Sul- } \\
\text { Teng }\end{array}$} & \multirow{2}{*}{$\begin{array}{l}\text { Bakau (Rizophora } \\
\text { apiculata /mucronata) }\end{array}$} & $\begin{array}{l}\text { Akar } \\
\text { muda }\end{array}$ & Obat muntaber \\
\hline & & & $\begin{array}{l}\text { Kulit } \\
\text { batang }\end{array}$ & Pewarna pukat/jala \\
\hline 2. & & $\begin{array}{l}\text { Kontau } \\
\text { granatum })\end{array} \quad$ (Xylocarphus & buah & $\begin{array}{l}\text { sebagai bahan pembuatan } \\
\text { bedak gatal/bedak dingin }\end{array}$ \\
\hline
\end{tabular}

Berdasarkan Tabel 1, dapat kita lihat bahwa pada dasarnya masyarakat telah mengetahui beberapa jenis tanaman yang bisa dijadikan sebagai bahan obat. Daun dan kulit Avicennia marina yang selanjutnya disebut api-api menurut masyarakat bisa untuk menyembuhkan sakit perut (diare) dan sakit asma. Untuk obat diare dan obat asma, caranya sangat mudah yaitu cukup dengan merebus beberapa lembar daun api-api lalu disaring dan air rebusannya diminum. Begitu juga dengan kulit pohon api-api, untuk bisa menyembuhkan diare cukup juga dengan meminum air rebusan kulit ini. Selain itu daun api-api juga bisa untuk menyembuhkan gatal-gatal. Untuk lebih jelasnya tentang daun ini dapat kita lihat pada gambar 3. 


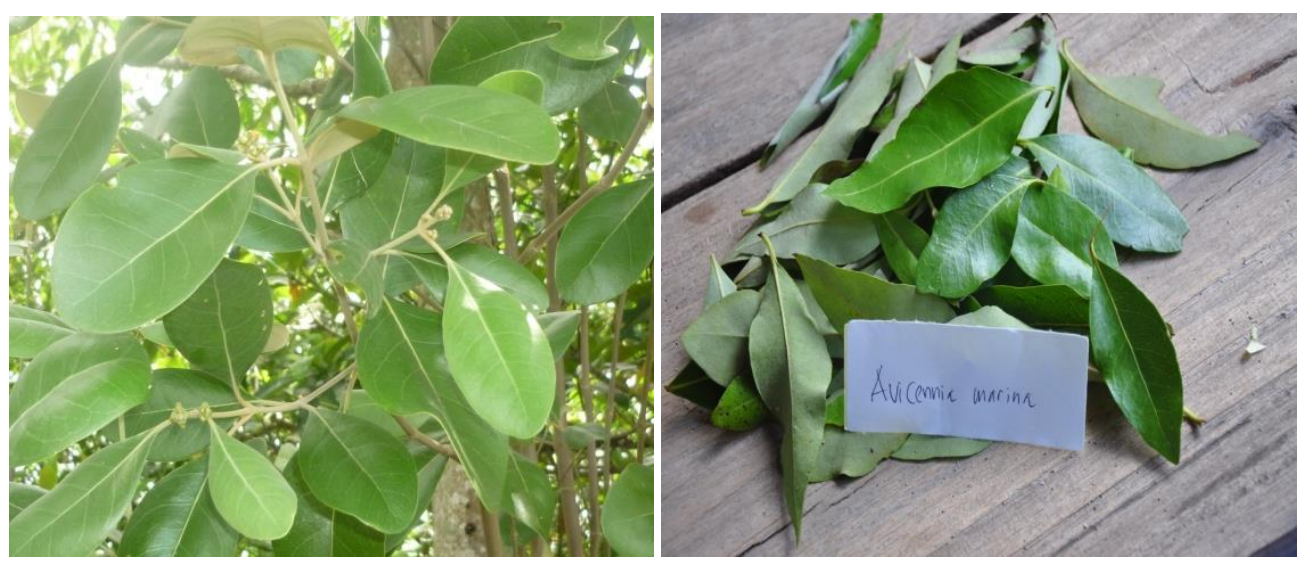

Gambar 3. Daun Api-api (Avicennia marina)

Senyawa aktif yang ditemukan pada daun api-api adalah 1.2 propadiene, neftalen, dimetiltetrametil suksinat, lucidol, isofilokladen, diosepan, dan nafto yang umumnya bersifat toksis pada dosis tertentu, serta memiliki sifat antibiotik dan anti serangga. Senyawa aktif pada berbagai jaringan tanaman api-api, yaitu alkaloid, flavonoid, tanin dan saponin merupakan senyawa potensial yang dapat dimanfaatkan sebagai bahan baku industri obat-obatan. Karena itu jaringan tanaman api-api berpotensi sebagai antibiotik untuk membantu penyembuhan luka (Wibowo dkk, 2009).

Tanaman bakau (Rhizophora $s p$ ) menurut masyarakat, daun dan akar mudanya bisa untuk menyembuhkan luka akibat tertusuk duri ikan dan gigitan kepiting, daunnya juga bisa untuk obat luka bakar dan kulitnya bisa sebagai bahan pewarna untuk jala/pukat. Tujuan pemberian warna pada jala ikan ini adalah untuk menyamarkan warna jala sehingga tidak terlihat oleh ikan.
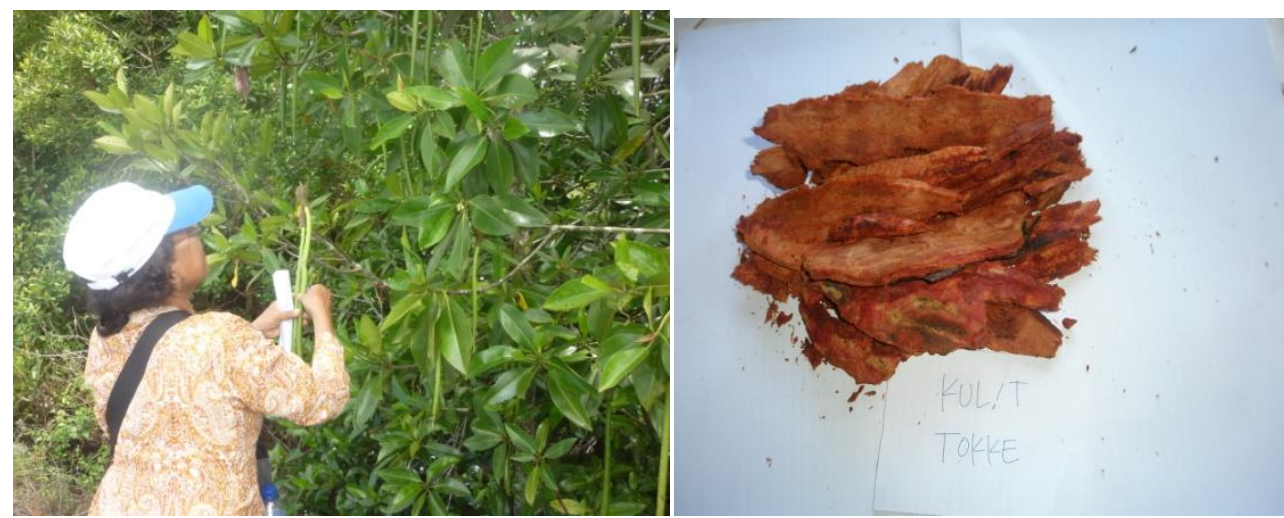

Gambar 4. Daun dan kulit pohon bakau

Buah tambu (Xylocarpus granatum) mempunyai khasiat untuk menyembuhan gatal-gatal, sebagai obat cacing juga untuk menghaluskan kulit. Caranya adalah dengan membuat buah ini menjadi bedak, buah dikupas terlebih dahulu, diiris tipis-tipis, dijemur dan setelah kering dicampur dengan beras yang telah dicuci dan dikeringkan dan dicampur dengan juga kunyit, lalu ditumbuk sampai halus dan dibuat bulatan-bulatan kecil. Untuk pengobatan, bedak buah tambu ini dicampur dengan air lalu dioleskan pada bagian tubuh yang sakit gatal, untuk obat cacing bedak dioleskan pada bagian perut sedang untuk 
menghaluskan kulit, bedak ini bisa dioleskan pada muka dan seluruh badan. Bedak buah tambu ini lebih sering digunakan oleh kaum perempuan atau ibu-ibu terutama di siang hari, karena selain memberikan efek dingin pada badan dan muka juga agar kulit tidak cepat terbakar karena sengatan matahari. Berikut ini adalah gambar buah buli.
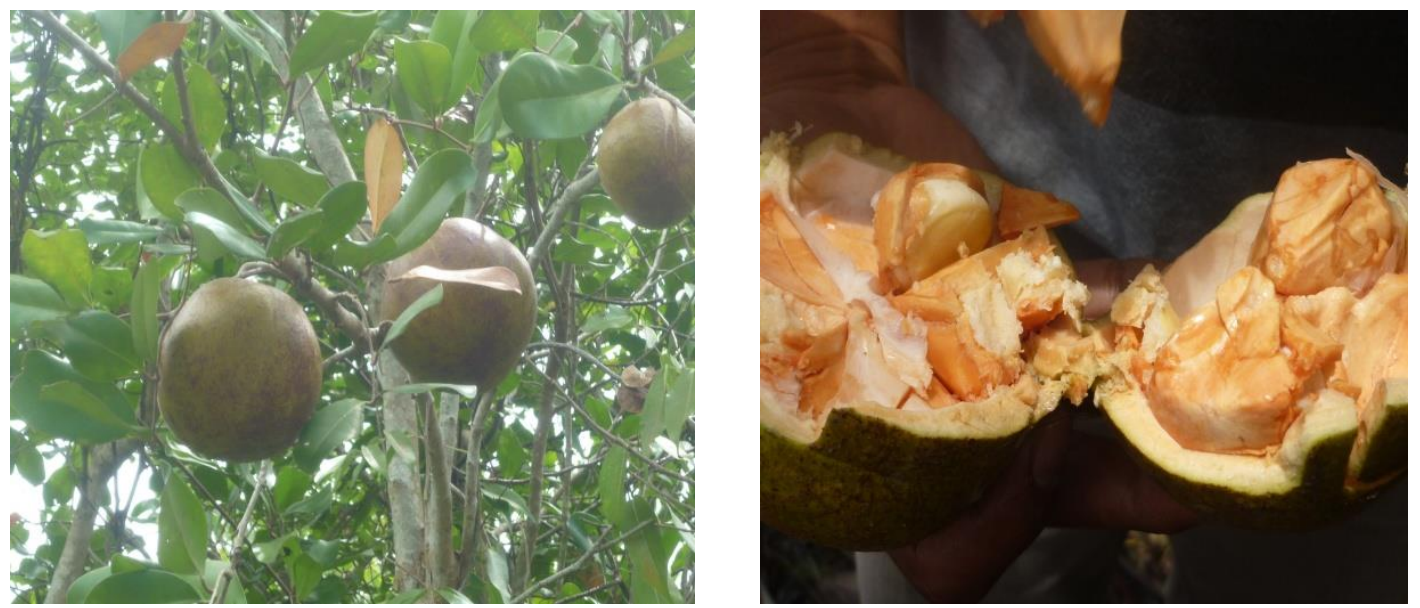

Gambar 5. Buah Buli (Xylocarphus granatum)

Buah sala-sala (Bruguiera gymnorrhiza) menurut masyarakat bisa menyembuhkan luka dalam atau muntah darah. Caranya yaitu ambil 3 (tiga) biji buahsalasala, kupas kulitnya dan belah menjadi (2) dua bagian dicampur dengan 3 (tiga) gelas air lalu dimasak hingga air rebusannya tinggal 1 (satu) gelas, kemudian diminum 3 (tiga) kali sehari.

Buah gandi-gandi (ceriops tagal) menurut masyarakat bisa digunakan sebagai pengganti sirih. Ini biasanya diperuntukkan untuk orang-orang yang telah lanjut usia, yang senang makan kapur sirih. Biasanya selain dicampur dengan sirih, juga dicampur dengan tembakau (nyirih). Berikut ini adalah gambar buah gandi-gandi.
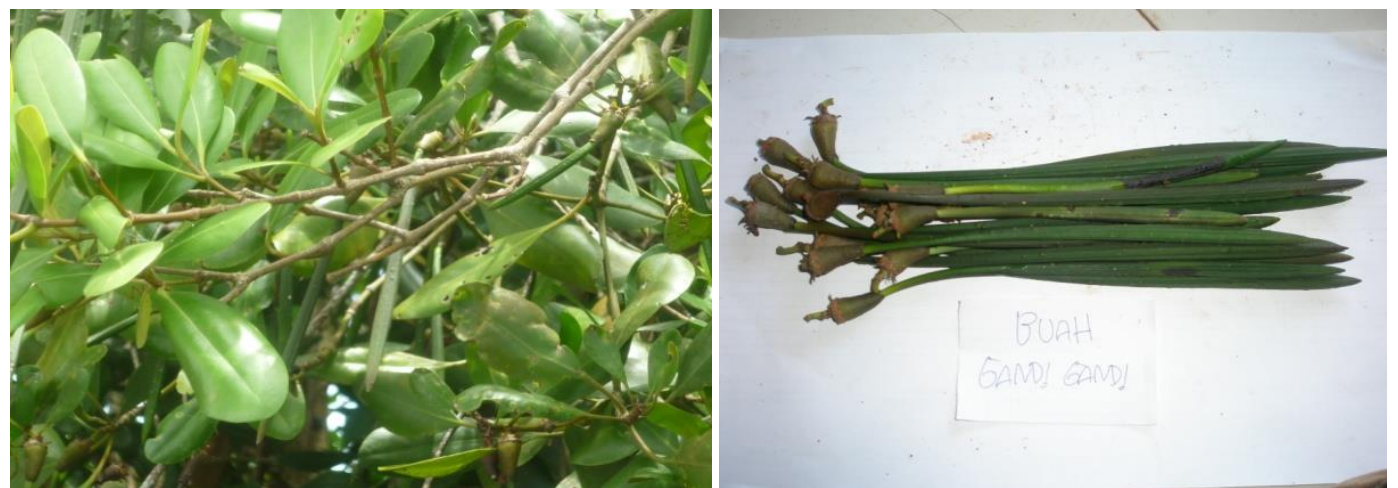

Gambar 6. Buah gandi-gandi (Ceriops tagal)

\section{KESIMPULAN}

Masyarakat di pesisir Sulawesi telah memanfaatkan mangrove sebagai bahan obat. Berdasarkan hasil penelitian yang telah dilakukan, diketahui terdapat beberapa jenis tanaman mangrove yang dapat digunakan oleh masyarakat sebagai bahan obat, yaitu 
Avicennia marina, Xylocarpus granatum, Ceriops tagal, Bruguiera gymnorrhiza, dan Rhizophora sp. Bagian yang dimanfaatkan dari jenis tumbuhan tersebut adalah daun, akar dan buah yang dapat digunakan untuk pengobatan pertama pada luka, sakit perut, muntaber dan lain sebagainya. Jenis yang diketahui dan dimanfaatkan oleh masyarakat ini masih minim mengingat ada banyak jenis tanaman mangrove lain yang dapat digunakan sebagai bahan obat. Oleh sebab itu, peran pemerintah setempat sangat diperlukan untuk menyebarluaskan informasi terkait jenis mangrove lain yang dapat digunakan sebagai bahan obat sehingga semakin memperkaya pengetahuan obat masyarakat dari bahan-bahan alam.

\section{DAFTAR PUSTAKA}

1. FAO (2007), FAO, 2007. The World's Mangroves 1980-2005. Forest Resources Assessment Working Paper No. 153. Food and Agriculture Organization of The United Nations. Rome.

2. Hamidu, H. (2009). Kajian etnobotani Suku Buton (Kasus masyarakat sekitar hutan Lambusango Kabupaten Buton Provinsi Sulawesi Tenggara). Skripsi. Fakultas Kehutanan. Institut Pertanian Bogor. (Tidak dipublikasikan).

3. Kusmana, C., Wilarso, S., Hilwan, I., Pamoengkas, P., Wibowo, C., Tiryana, T., Triswanto, A., Yunasfi dan Hamzah. 2003. Teknik Rehabilitasi Mangrove. Fak. Kehutanan IPB

4. Kusmana, C., Istomo, C.W., Sri, W.B.R., Iskandar, Z.S., Tatang, T., Sukristijono, S., 2008. Manual Silvikultur Mangrove di Indonesia. Departemen Kehutanan Republik Indonesia dan Korea International Cooperation Agency (KOICA). Jakarta.

5. Noorcahyati. 2012. Tumbuhan Berkhasiat Obat Etnis Asli Kalimantan. Balai Penelitian Teknologi Konservasi Sumber Daya Alam. Badan Litbang Kementrian Kehutanan. Samboja.

6. Notoatmodjo, S. 2007. Promosi Kesehatan dan Ilmu Perilaku . Jakarta : Rineka Cipta

7. Purnobasuki, H., 2004. Potensi Mangrove sebagai Tanaman Obat. http://www.irwantoshut.com/

8. Purwanto, Y., 2000. Etnobotani dan konservasi plasma nutfah hortikultura : peran sistem pengetahuan lokal pada pengembangan dan pengelolaannya. Prosiding Seminar Hari Cintapuspa dan Satwa Nasional. http://repository.ipb.ac.id/bitstream/handle /123456789/52308/ Daftar_Pustaka.pdf.

9. Suryadharma, I. (2008). Diktat kuliah etnobotani. Jurusan Pendidikan Biologi. Fakultas Matematikan dan Ilmu Pengetahuan Alam. Yogyakarta: Universitas Negeri Yogyakarta.

10. Wibowo C., Kusmana, C., Suryani, A., Hartati, Y., Oktadiyani, P. 2009. Pemanfaatan Pohon Mangrove Api-Api (Avicennia spp.) sebagai bahan Pangan dan Obat. [Prosiding Seminar Hasil-Hasil penelitian]. Bogor: Fakultas Kehutanan, Institut Pertanian Bogor. 